\title{
Erratum to: A Comparative Study of Finland and Chile: the Culture-Dependent Significance of the Individual and Interindividual Levels of the Mathematics-Related Affect
}

Laura Tuohilampi ${ }^{1}$ - Anu Laine ${ }^{1}$. Markku S. Hannula ${ }^{2}$ - Leonor Varas ${ }^{2}$

Published online: 12 May 2016

(C) Ministry of Science and Technology, Taiwan 2016

\section{Erratum to: Int $\mathbf{J}$ of Sci and Math Educ DOI 10.1007/s10763-015-9639-0}

The article was updated. Incomplete references in text and reference list were corrected. 